Article

\title{
Sport and Incarceration: Theoretical Considerations for Sport for Development Research
}

\author{
Mark Norman \\ Department of Health, Aging \& Society, McMaster University, Hamilton, L8S 4L8, Canada; E-Mail: normam2@mcmaster.ca
}

Submitted: 30 December 2019 | Accepted: 23 March 2020 | Published: 17 August 2020

\begin{abstract}
Despite a rapid expansion in research on Sport for Development (SfD), there remain numerous untapped veins of exploration. This article makes a novel argument for increasing the theoretical and substantive depth of SfD research by linking it to the relatively small, yet developing, body of literature on sport and incarceration. Drawing from the emergent field of carceral geography and the literature on prison sport, this article provides critical theoretical considerations for SfD programs that occur in 'compact' sites of confinement, such as prisons or refugee camps, or are enmeshed in 'diffuse' manifestations of carcerality. Given the structures of inequality that have led to the confinement of more than 13 million people in prisons, refugee camps, and migrant detention centres across the globe, as well as the multitude of ways that groups and individuals are criminalized and stigmatized in community settings, there are compelling reasons for SfD research to more deeply engage with concerns of space and carcerality as they relate to sport. As such, this article provides an important foundation for future analyses of SfD and carcerality, and signposts some potential ways forward for a deepening of theoretical perspectives in SfD research.
\end{abstract}

\section{Keywords}

carceral geography; incarceration; prison sport; space; sport for development

\section{Issue}

This article is part of the issue "Sport for Development: Opening Transdisciplinary and Intersectoral Perspectives" edited by Pascal Delheye (Ghent University, Belgium), Kirsten Verkooijen (Wageningen University \& Research, The Netherlands), Dan Parnell (University of Liverpool, UK), John Hayton (Northumbria University, UK) and Reinhard Haudenhuyse (Vrije Universiteit Brussel, Belgium).

(C) 2020 by the author; licensee Cogitatio (Lisbon, Portugal). This article is licensed under a Creative Commons Attribution 4.0 International License (CC BY).

\section{Introduction}

Despite a rapid expansion in research on Sport for Development $(\mathrm{SfD})$, there remain numerous untapped veins of exploration for scholars. One area that has, thus far, been largely neglected in the SfD literature, is sport and other diverse forms of physical culture (hereafter collectively referred to as 'sport'), as well as other forms of recreation and leisure, in prisons and other sites of incarceration. This article makes a novel argument for increasing the theoretical and substantive depth of SfD research by linking it to the relatively small, yet developing, body of literature on sport, leisure, and incarceration. In doing so, it brings the SfD literature into dialogue with critical theoretical developments in criminology and human ge- ography, specifically the emergent field of carceral geography, and advocates for a deeper consideration of space and carcerality within SfD research.

There are compelling reasons to consider and develop connections between these bodies of literature. There are over 10.7 million people held in prison or pre-trial detention around the globe (Walmsley, 2018), as well as an additional 2.6 million refugees living in camps (UNHCR, 2018) and an uncertain number of migrants forcibly confined in over 2,200 detention camps in 100 countries (Global Detention Project, 2019). While there is considerable variation of conditions within and between these types of confinement, these carceral spaces share many characteristics-including the prominent social role of sport, and in some instances SfD inter- 
ventions, in the daily lives of many people living therein. Further, and critical for the theoretical analysis of SfD and incarceration, carceral geographers have recognized how the spatial characteristics and embodied effects of incarceration are manifested in a myriad of 'diffuse' ways beyond these physical sites (Moran, Turner, \& Schliehe, 2018). As this article details, there are numerous ways in which these theoretical developments contribute to a more critical analysis of some SfD interventions.

As such, this article develops some initial theoretical connections between the literatures on SfD, prison sport, and carceral geography. The article is theoretical in its orientation, drawing from existing literature to perform its analysis. However, much of the work on carceral space and sport that is discussed in this article is derived from the author's broad, ongoing investigations into the social meanings and organization of sport in Canadian prisons and youth custody centres. The article begins by sketching some initial points of connection between research on SfD and prison sport, before introducing theoretical perspectives from carceral geography that provide insights into sport and carcerality. The bulk of the article is devoted to a deep theoretical consideration of critical considerations for SfD research through the lens of compact and diffuse models of carcerality. These analyses provide novel insights, raise critical questions, and signpost ways forward for a deepening of theoretical perspectives in SfD research.

\section{SfD and Prison Sport Research: Initial Points of Connection}

SfD, despite its similarities to historical 'sport-for-good' efforts, is a relatively recent phenomenon that focuses on leveraging sport to achieve a wide array of social, educational and health outcomes (Darnell, 2012; Darnell, Field, \& Kidd, 2019). SfD interventions are typically implemented in Global South countries with funding and ideological support from governmental, nongovernmental and corporate donors based in the Global North (Darnell, 2012); however, the logic of SfD is increasingly being applied to programs targeting supposedly 'vulnerable' or 'at-risk' groups in Global North countries (e.g., Hayhurst \& Giles, 2013; Nols, Haudenhuyse, \& Theeboom, 2017; Scherer, Koch, \& Holt, 2016). Scholarship on SfD has proliferated in the past two decades (Schulenkorf, Sherry, \& Rowe, 2016). While a recent overview of SfD research (Darnell, Chawansky, Marchesseault, Holmes, \& Hayhurst, 2018) notes a paucity of critical theoretical perspectives among most SfD scholarship, researchers have developed critical analyses of SfD using diverse approaches, such as political economy (Darnell, 2012), postcolonial feminism (Hayhurst, 2016), critical race theory (Forde, 2015), and the Capabilities Approach (Dao \& Smith, 2019; Darnell \& Dao, 2017), among others. Less common, but significant, are analyses of SfD spaces (e.g., Forde, Waldman, Hayhurst, \& Frisby, 2017; Oxford \& Spaaij, 2017), which will be discussed in greater detail in a later section.
At first glance, there may seem to be little to link SfD with sport and physical recreation in prisons. Unlike SfD, prison sport is not institutionalized-rather, its form and availability will vary widely depending on the jurisdiction, the type and security level of confinement, and the prisoner subculture in specific institutions (Norman, 2018a). Further, although some youth custody institutions provide sport initiatives that are, like much SfD programming, explicitly linked with specific social or pedagogical outcomes (Meek, 2014; Meek \& Lewis, 2014; Norman, Ricciardelli, \& Sonoda, 2020), in adult institutions activities are often detached from such intentions and are viewed by staff a way for prisoners to expend aggression and thus be more docile (Martos-García, Devís-Devís, \& Sparkes, 2009; Norman, 2017). Indeed, there is scant reference to prison sport in the SfD literature. The most explicit connection between the two was provided in a study by Gallant, Sherry, and Nicholson (2015), who framed the outcomes and management of sport participation by prisoners - such as improved health, skill development that could contribute to desistance, and partnership between prisons and external sport organizationsas SfD. Although the authors did not deeply develop this connection or situate their study in the SfD literature, their explicit linking of prison sport and SfD nonetheless provides a valuable entrée to bridging these areas of study.

Whereas SfD is a burgeoning realm of research (Schulenkorf et al., 2016), socio-cultural research on sport in prisons remains relatively limited. Among the major sociological themes in the existing literature are the contributions of sport to: constructions of hegemonic masculinity in male prisons (Andrews \& Andrews, 2003; Sabo, 2001), the control and management of prison populations (Martos-García et al., 2009; Norman, 2017) and prisoners' micro-resistances to these regimes of social control (Martinez-Merino, Martos-García, Lozano-Sufrategui, Martín-González, \& Usabiaga, 2019; Norman, 2017; Norman \& Andrews, 2019), and the likelihood of prisoners desisting from crime after being released into the community (Meek, 2014; Meek \& Lewis, 2014). A new vein of recent research (Gacek, 2017; Norman, 2019; Norman \& Andrews, 2019), which this article builds upon, explicitly engages with theoretical developments in carceral geography to consider the spatial significance of sport in prisons.

Yet, despite their differences, there are a number of substantial ways in which these areas of study potentially align. For example, the SfD sector's major focus on providing programming in the Global South parallels a trend in which, with the notable exception of the United States, the highest prison populations and rates of incarceration are found in BRIC or Global South countries (Walmsley, 2018). Meanwhile, as incarceration rates of girls and women have skyrocketed by over $50 \%$ since 2000 (Walmsley, 2017), SfD's core interest in gender equality and female empowerment, and important critiques thereof (Chawansky \& Hayhurst, 2015), take on 
relevance in prison sport programs. Further, both $\mathrm{SfD}$ and prison sport can be rationalized or analyzed through a human rights lens. The SfD sector has placed a strong emphasis on sport as a human right and/or a vehicle toward achieving human rights (Darnell, 2012). In prisons, the right to outdoor recreation and exercise is enshrined in various global guidelines and policies (Norman, 2018a) and its significance to prisoners' health, social life, and dignity is acknowledged in some considerations of human rights in prisons (Coyle \& Fair, 2018).

While such overlapping interests provide a small window into how the SfD and prison sport literatures might inform each other and offer some fertile ground for further analysis and critique, this article argues that there are deeper theoretical reasons to link these areas of research. In so doing, the article suggests that research on SfD could more deeply consider both its spatial significance and its relation, in at least some instances, to carcerality. In these efforts, the article draws inspiration from Darnell and colleagues' critique of the narrow focus of the SfD literature and call for critical scholars to adopt "an increasingly holistic approach to [SfD] research, rather than an exclusive or bordered one" (Darnell et al., 2018, p. 147). To perform this analysis, the article draws heavily from theoretical developments in carceral geography, most notably the distinction between compact and diffuse carceral models (Moran et al., 2018).

\section{Carceral Geography: Novel Theoretical Insights into Sport}

Carceral geography is an emergent subfield of human geography that is concerned with the critical examination of the "the nature of carceral systems and experiences within them, the spatial geographies of carceral systems, and the relationship between the carceral and an increasingly punitive state" (Moran, 2015, p. 2). Philo's (2012, p. 4) influential articulation of this area of study considered its focus to be "the spaces set aside for 'securing' detaining, locking up/away-problematic populations of one kind or another." However, carceral geographers have demonstrated that the effects and characteristics of incarceration spread far beyond the physical boundaries of sites of confinement and, further, that there is significant mobility of bodies, material goods, and ideas "within, between, and beyond carceral institutions" (Moran, 2015, p. 72). Carceral geography can be understood as focusing on two closely related models of carcerality: compact and diffuse (Moran et al., 2018). The inspiration for analyzing these carceral models is the work of Michel Foucault (1977), who argued that the social control apparatuses of the prison "merge and intertwine wider society with the carceral in a diffuse way...via 'carceral circles,' which, like ripples in water, extend far from the prison" (Moran et al., 2018, p. 668).

Drawing on a wide range of theoretical and disciplinary perspectives, carceral geographers have deep- ened and extended Foucault's postulation by analyzing a variety of "other compact carceral sites [beyond the prison] which resemble the prison both in functional form and in mode of operation" (Moran et al., 2018, p. 669) and by considering how carcerality is manifested in diffuse ways through social means (e.g., the social stigma faced by former prisoners) or technological apparatuses (e.g., surveilled spaces for youth deemed 'atrisk' of criminal behaviour). Further, critical scholars have increasingly recognized how spaces of incarceration engender embodied practices and corporeal transformations that endure far beyond the period of confinement and can contribute to social stigma or difficulty adjusting to life in the community (Caputo-Levine, 2013; Moran, 2015). The horizons for critical analysis of various SfD interventions are significantly broadened by the insight that compact carceral sites share notable similarities and that carcerality is manifested and embodied in diffuse forms beyond these spaces of confinement. Further, carceral geography provides an intriguing lens through which to engage in nuanced analyses of carcerality within specific sport spaces.

The handful of studies that consider sport within a carceral geography framework provide some important entry points for theoretically deepening SfD research. Gacek's (2017, p. 73) analysis of Canadian male prisoners' 'imaginative mobilities' included a nuanced consideration of how sport and recreation enabled "inmates to psychologically enter the inner spaces of their minds to avoid and distance themselves from the prison life that exists 'outside' their anatomical control." According to Gacek (2017, p. 82), these activities enabled prisoners to psychologically transcend the boundaries of the prison, stave off boredom and enjoy pleasurable (imaginary) experiences-and, in so doing, "to endure the boredom, mundanity, uncertainty, and (in)security of the prison culture." Norman and Andrews (2019) similarly considered how prisoners used sport to produce spaces that enabled them to cope with their confinement, while also recognizing how sport shaped prison spaces in unique and sometimes contradictory ways, including promoting violence or exclusion and "asserting [prisoner] agency in the face of administrative control" (Norman \& Andrews, 2019, p. 459). Finally, Norman (2019) examined yoga as an alternative form of physical culture that facilitates contact between the 'inside' (prisoners) and 'outside' (members of the community), creates spaces for otherwise suppressed emotional expression, and, notable for this article, interacts outside the prison with diffuse carceral effects such as the stigmatization of former prisoners. While sharing a general focus on sport in carceral space, these studies also suggest the possibilities for a carceral geography perspective to deepen the analysis of specific forms of sport and human movement within particular carceral sites.

Given the great social and geographic diversity of SfD programs, there are numerous ways in which considerations of carcerality and space might enrich the critical 
analysis of SfD. This article represents an initial consideration of these, with the aim of laying a foundation for deeper future research in this area.

\section{SfD, Prison Sport and Carceral Space: Theoretical Considerations}

Despite the significance of socially-produced space to SfD, spatial analyses are limited in the SfD literature. Scholars have rightly noted that complex phenomenon of SfD must be understood as occurring "across local, global and transnational levels within the [SfD] sector" (Giulianotti, 2011, p. 52), while specific SfD interventions have been found to cultivate 'safe spaces' for emotional expression, psychosocial wellbeing, or social support (e.g., Oxford \& Spaaii, 2017). Using vignettes arising from their research, Forde et al. (2017) provided a compelling insight into considering how SfD programs facilitate a variety of types of movement in and through diverse spaces and, in so doing, produce complex and contradictory spatial meanings related to neoliberalism, community, gender, and social injustice. SfD research has thus only tentatively linked to potentially-relevant developments in the broader field of sport geography, such as disciplinary surveillance and resistance in sport spaces (Bale, 1993), the contradictory meanings of physical activity as a 'therapeutic landscape' (van Ingen, 2004), the politics of health promotion through physical activity space (Fusco, 2007), or emerging non-representational analyses of movement, time and space (Andrews, 2017). This article contributes to initial efforts to deepen the connection between SfD and sport geography research through its engagement with the prison sport and carceral geography literatures.

\subsection{SfD and Compact Forms of Carcerality}

A clear entry point to connecting the prison sport and SfD literatures is found where similarities exist between prisons and various other compact carceral sites SfD interventions occur. Indeed, in his research on prison sport, Norman (2017, 2018a, 2018b) has argued that there may be considerable value in comparative research on sport across a range of 'total institutions' - such as military facilities, youth custody centres, and refugee camps - that share carceral features. Though not explicitly describing them as compact carceral sites, researchers have examined the social meanings of sport in a variety of spaces fitting this description, including camps for refugees and migrants (Dukic, McDonald, \& Spaaij, 2017; McGee \& Pelham, 2018; Spaaij et al., 2019) and various historical sites, such as mental institutions (Ellis, 2013), Japanese internment camps in the United States (Mullan, 1999), and Canadian residential schools for Indigenous youth (Forsyth, 2013; Te Hiwi \& Forsyth, 2017). In cases where SfD programs have operated in compact sites, carceral geography offers researchers rich insights for analyzing the oppressive daily experiences of confined people and the potential liberatory or punitive effects that sport may generate.

A notable feature of certain compact carceral sites is the social construction of time and its relation to space. Prisoners, for example, experience time both as a fixed passage of years, months and days ('clock time') and in temporal flows, relating to the monotonous daily routine of prison life, which may be made to feel faster by tactically engaging in particular activities (Moran, 2012). As such, prisoners often speak of 'killing' or 'passing' time and describe particular spatial and temporal experiences as facilitating 'hard' or 'easy' time (Wahidin, 2006). In sites of incarceration, "the embodied experience of time is inextricably bound up with the embodied experience of space, and vice versa" (Moran, 2012, p. 310). Further, at a macro-level, Gill, Conlon, Moran, and Burridge (2018) noted that contemporary carcerality is defined in part by the relationship between time, space, and global structures of inequality, leading to:

The organized warehousing of sections of the global population forced to wait purposelessly on the margins of developed economies in prisons, camps, slums and detention centres in response to global politicaleconomic conditions. The calibration of carceral space to accommodate this wastage, over and above aspirations to reform or even punish the incarcerated, is a hallmark of the neoliberal carceral landscape. (Gill et al., 2018, p. 190)

Some prison sport literature has engaged with questions of time, space, and carcerality in ways that may be translatable to SfD research. Notably, some research on prison sport has identified its impact on the perceived passage of time as one of the most significant outcomes for prisoner participants (Gallant et al., 2015; MartosGarcía et al., 2009; Norman \& Andrews, 2019; Sabo, 2001). At an instrumental level, Gallant et al. (2015, p. 53) suggested that prison sport programs "may distract inmates...[and] positively impact individual mood as well as the overall mood of the facility." More critically, Gacek (2017) argued that sport and recreational activities could not just help pass time, but also be a form of 'imaginative mobility' that could temporarily transport the participant beyond the daily frustrations of their incarceration. Building upon these findings, Norman and Andrews (2019, p. 462) found that prisoners' engagement with sport could facilitate stillness and mental escape, and in so doing help them "cope with the spatial and temporal restrictions placed upon them, both in their regular daily routine and in exceptional circumstances such as being confined to their cells during a lockdown." Research on leisure in prisons (Fortune \& Whyte, 2011; Yuen, Arai, \& Fortune, 2012), meanwhile, has highlighted the possibility for leisure activities to bring prisoners and community members together in a shared venture and, in so doing, increase the possibility for carceral spaces to "be reimagined as spaces that are vital for promoting commu- 
nity cohesion and increasing social acceptance" (Fortune \& Whyte, 2011, p. 31).

These findings have significant implications for understanding the experiences of $\mathrm{SfD}$ participants living in compact carceral sites, such as refugee camps. Insights about time and carceral space raise questions about both the liberatory and punitive possibilities of sport in such environments. For example, might an SfD program in a refugee camp enable participants to experience time and space in more pleasant ways? Or, given the global pressures within the SfD sector to produce 'positive' outcomes that may not align with participants' experiences or interests (Donnelly, Atkinson, Boyle, \& Szto, 2011), might an SfD program in a compact carceral space reinforce the slow passage of time and bureaucratic spatial management of residents' daily lives? And, in line with critiques of SfD's enmeshment in global forms of structural inequality and circuits of capital (Darnell et al., 2018; Darnell \& Dao, 2017; Forde et al., 2017; Oxford \& Spaaij, 2017), to what extent does SfD in compact spaces contribute to or challenge "the institutionalized disposal of time...[and] wastage of human life" (Gill et al., 2018, p. 190) that characterizes contemporary carceral logic?

A further consideration arises from the possibility for SfD or prison sport programs to operate as a form of social control within a compact carceral site. Carceral spaces, both compact and diffuse, are characterized by "the deployment of a new range of strategies of social control and coercion" (Moran et al., 2018). Prison sport studies (Martos-García et al., 2009; Meek, 2014; Norman, 2015, 2017) have found that prison administrators may view sport as a means for diverting prisoners' energy and attention away from their punitive conditions of confinement, making sport participation a short-term management tool "with no implications for the long-term development of the prisoner in terms of their rehabilitation into...society at the end of their sentence" (Martos-García et al., 2009, p. 86). Further, the opportunity to engage in certain forms of sport (and the possibility of this privilege being withdrawn) may be used as an incentive to induce particular forms of behaviour (Meek, 2014; Norman, 2017), while the instrumental rationales underpinning sport provision may contribute to a broader correctional philosophy that sees individual choice, rather than structural factors, as the sole cause of criminal behaviour (Norman, 2015). In such a context, specific uses of sport may represent resistance, however small, against regimes of control. For example, prisoners may participate in weightlifting or bodybuilding to develop muscular physiques that visibly represent the threat of violence (Norman, 2017), play sport to demonstrate agency in the face of inherently disempowering experiences of incarceration (Martinez-Merino et al., 2019), repurpose recreation spaces or equipment for illicit means (Norman, 2017), or simply shape the experience of carceral time and space in more pleasurable ways (Gacek, 2017; Norman \& Andrews, 2019).
Historical research on compact carceral sites offers further insight into the operation of social control and resistance in these spaces through sport. For example, Indian residential schools - which were governmentfunded, church-run boarding schools for Indigenous children in Canada, operating between 1880 and 1996used sport as part of their broader agenda to eradicate Indigenous culture and assimilate youth into EuroCanadian society (Forsyth, 2013). Students, who were often forcibly removed from their families and forced to endure abusive and austere treatment, participated in physical training exercises and military drills that were intended to control their bodies, assimilate them into Canadian culture, and teach them deference to authority (Forsyth, 2013); meanwhile, boys' ice hockey, which flourished at some residential schools, was viewed by administrators as a way to generate "student compliance, obedience, and discipline...[translating] into wellbehaved, moral, and disciplined boys off the ice" (Te Hiwi \& Forsyth, 2017, p. 82). Yet, participation in sport could bring benefits and prestige, as well as a temporary relief from the pains of the carceral experience. As Te Hiwi and Forsyth (2017, pp. 107-108) noted, despite the social control impetus behind an ice hockey program at one residential school, "many boys took up the opportunity for fun, competition, and recreation, and to escape from the struggles of daily life at the school, albeit temporarily." Similarly, for some Japanese Americans held in internment camps during WW2, participation in or spectatorship of competitive baseball matches represented an important social activity and "a way to deny the oppressive facts of wartime imprisonment" (Mullan, 1999, p. 17).

These insights on social control and resistance in carceral spaces provide an important point of connection with existing $S f D$ research, which has recognized that sport programs may attempt to socialize young people into hegemonic values and promote a neoliberal view of individual responsibility for 'development' (Darnell, 2012; Darnell \& Dao, 2017; Hayhurst \& Giles, 2013). Yet, there is scope for a deeper investigation of how coercion and autonomy operate in SfD contexts. How might SfD interventions, like sport programs in carceral facilities, be "both a carrot and a stick..., sometimes being viewed as an attractive activity for prisoners that can also promote good behaviour, and other times being withheld, as a form of punishment" (Norman, 2017, p. 603)? And how might SfD participants, particularly in compact carceral sites in which their agency is severely curtailed, find ways to engage in tactical forms of micro-resistance to the oppression experienced in their daily lives (MartinezMerino et al., 2019; Norman, 2017)? In this vein of analysis, carceral geography's sensitivity to the ways in which carceral time and space are embodied (Moran, 2012) offers a useful entry to considering how SfD programs in compact sites inscribe the carceral upon the bodies of participants and, notably, how participants can use sport in unintended ways to produce spaces that are sites of pleasurable or meaningful experiences. Such ques- 
tions have begun to be explored in prison sport research (Norman, 2019; Norman \& Andrews, 2019), and would align well with cutting edge theoretical concerns in SfD research around human movement and space (Forde et al., 2017), "hope and social change" through sport (Forde \& Kota, 2016, p. 445), and "questions of socialization, identity, bio-politics, and the body [as they are] produced and constrained within the terrain (both material and discursive) of the [SfD] sector" (Darnell et al., 2018, p. 140).

\section{2. $S f D$ and Diffuse Forms of Carcerality}

While some SfD initiatives occur at compact carceral sites, these are clearly the minority of programs. Yet, there are a myriad of ways in which diffuse forms of carcerality may be manifested in and through SfD interventions. Firstly, there are impacts of imprisonment felt by individuals and communities beyond the physical site of the prison. As Moran et al. $(2018$, p. 670) explain, "techniques and technologies of confinement leach into everyday domestic, street, and institutional spaces with which both former inmates and their loved ones...come into contact." This may be seen in a variety of SfD programs in Global North countries for 'vulnerable' or 'at-risk' (usually young) people (e.g., Bustad \& Andrews, 2017; Nols et al., 2017; Scherer et al., 2016; Schulenkorf et al., 2016), a group that may well include participants who have been incarcerated or who have been subjected to diffuse manifestations of carcerality such as police surveillance. Further, sport activities are sometimes used in community programs that exist as alternatives to incarcerating young people (e.g., Joseph, 2015); yet, as Fishwick and Wearing (2017, pp. 49-50) demonstrated, such diversionary programs, although avoiding direct incarceration, nonetheless "govern and direct mobilities - that is, where young people go (or do not go)...creating 'liminal' spaces of semi-confinement." Lastly, returning to Gill et al. (2018), spatially-and economically-segregated slums or urban townships sit alongside compact carceral sites as spaces for "the organized warehousing of sections of the global population forced to wait purposelessly on the margins of developed economies" (Gill et al., 2018, p. 190). Some scholars have fruitfully examined the deployment of SfD programs in slums (Forde \& Kota, 2016; Willis, 2000), yet critical analysis of sport, poverty and urban space remains limited (Gruneau, 2015).

In the SfD literature, Scherer et al. (2016) offer one of the most significant considerations of diffuse carceral effects in their examination of an urban SfD program in Canada. They observed that the young men in their study were "subjected to a nearly insurmountable set of obstacles associated with an urban carceral network" (Scherer et al., 2016, p. 190) and argued that some formerly incarcerated men "are still doing hard time in the 'free' market as a result of the additional punitive conditions that they are subjected to in the carceral city"
(Scherer et al., 2016, p. 193). Another example of the intersections of diffuse carcerality with SfD can be seen in Midnight Basketball programs in the United States in the 1990s (Hartmann, 2001). These programs can be considered a forerunner of $\mathrm{SfD}$, for although "there may not have been a direct through-line from Midnight Basketball to the emerging global [SfD] sector, but they inhabited the same conceptual and historical frame" (Darnell et al., 2019 , p. 6). Midnight Basketball targeted "poor, innercity youth and young men of color" in an attempt to reduce crime and drug use (Hartmann, 2001, p. 350). These programs not only racialized and criminalized participants, but also created spaces of surveillance and diffuse carcerality: early iterations featured prison guards as coaches and police vehicles parked prominently outside gyms, while programs typically had a significant presence of uniformed police officers at each session (Hartmann, 2001). Yet, within diffuse carceral spaces such as slums, sport-albeit, often outside of or in opposition to institutionalized SfD programs and organizations-may be part of larger efforts by residents to create local solidarity, advocate for social change, or create spaces that develop collective hope and resistance (Forde \& Kota, 2016; Gruneau, 2015).

Another important characteristic of diffuse carcerality is that the effects of incarceration are "mobile and embodied" (Moran et al., 2018, p. 670)-that is, confinement can generate bodily practices and comportments, or what Caputo-Levine (2013) terms the 'carceral habitus,' that are carried with individuals after they leave the physical site. As Moran (2015, p. 35) explained, "incarceration has a particular set of prison-dependent, tell-tale inscriptions [and] the stigma prisoners may experience after release is to some extent enabled by the lack of fit' between these inscriptions and the circumstances of release." This revelation has implications for sport practices within and beyond carceral spaces. For example, in a consideration of the spatial dynamics of yoga practice during and after incarceration, Norman (2019) identified a potential incompatibility between former prisoners' 'carceral habitus' and the (racialized and classed) spaces of private yoga studios where they might seek to practice upon their release. More positively, research on Stride Circles-communities of volunteers and incarcerated women formed through weekly leisure nights at a prison in Ontario, Canada-found that the post-release continuity of the Circles enabled former prisoners to navigate enduring carceral effects, such as social isolation, difficulty adjusting to life on the 'outside,' and stigma (Fortune, Thompson, Pedlar, \& Yuen, 2010).

In the case of SfD, these insights raise questions about how sport spaces are constructed in ways that might create or exacerbate social marginalization. For example, understanding how immersion in carceral spaces or exposure to diffuse forms of carcerality can inscribe the body in ways that are stigmatizing in other contexts (Moran, 2015) could enable more nuanced critiques of various SfD or sport and social inclusion initiatives. 
Indeed, many sport interventions operate from a 'deficit discourse,' "which positions 'at-risk' youth, refugees, immigrants or the poor as fundamentally lacking in skills, abilities or motivations" (Darnell et al., 2018, p. 6; see also Nols et al., 2017; Spaaij, 2011). In such a context, how might the sport participation of refugees and asylum seekers, many of whom have extensive experience living in carceral spaces such as camps or detention centres (e.g., Spaaij, 2011; Spaaij et al., 2019), be affected by their embodied experience of involuntary confinement? And how might this carceral habitus interact with the 'football habitus,' or other sport, which has been shown to facilitate social interaction and engagement by asylum seekers in sport-based social inclusion programs (Dukic et al., 2017)? Similar questions might be asked of SfD interventions aimed at reintegrating child soldiers (e.g., Dyck, 2011; Kath \& van Buuren, 2013) who carry with them into sport spaces the embodied experiences of immersion in carceral (para)military cultures from a young age.

Another pertinent line of inquiry relates to SfD or sport-based social inclusion programs geared at urban (often racialized) youth who are criminalized in various ways (e.g., Bustad \& Andrews, 2017; Hartmann, 2001; Scherer et al., 2016). Indeed, Scherer et al. (2016) highlighted how some participants at an inner city SfD program experienced and embodied diffuse effects of past confinement through limited employment prospects and social stigma; and Bustad and Andrews' (2017) analysis of an American Police Athletic League demonstrated how sport-based social inclusion efforts can be used to attempt to control poor, racialized youth in a broader context of neoliberal carcerality. Conversely, the fact that leisure may provide a site for developing intentional communities that endure beyond the period of incarceration (Fortune et al., 2010) opens up intriguing possibilities for combatting the detrimental impacts of diffuse carcerality through SfD programs. In either case, such insights are crucial for better understanding the diverse experiences of SfD participants in order to "connect everyday lives to the broader contexts of sport, development and [SfD]...[and] developing an understanding of the complexities of [SfD]" (Darnell et al., 2018, p. 11). Developing deeper theoretical connections along these lines will enhance not only the SfD literature, but also the significant body of research on sport and social inclusion.

\section{Conclusion}

Scholars have increasingly argued that we have entered a 'carceral age' that is "characterized by unprecedented fluidity between forms of confinement, be they statesanctioned, quasi-legal, ad-hoc, illicit, spatially fixed, mobile, embodied or imagined, and in which the scale of deployment of carceral techniques and infrastructures demands critical attention" (Moran et al., 2018, p. 668). As has been extensively discussed in this article, carcerality is manifested not only in compact sites of confine- ment, but in a host of diffuse ways that, to use Foucault's (1977) metaphor, 'ripple' outward from these spaces and shape experiences and relationships on a much wider scale. Coincidentally, the idea of a 'ripple effect' has also been deployed in the SfD literature to describe how social changes that occur at a local level may have broader sociopolitical effects (Sugden, 2010). These two very different applications of the same metaphor point to relevant questions arising from this article. Specifically, are there compelling reasons to build theoretical bridges between the study of sport in carceral spaces-or, perhaps, a 'carceral geography of sport' - and SfD? And, if so, are there practical considerations for SfD research that arise from this connection? It is hoped that this article has answered the first question in the affirmative. As for the latter question, this article offers a number of new lines of consideration for SfD researchers.

Firstly, a greater recognition of how some SfD programs occur in carceral spaces, including compact carceral spaces beyond the prison, will enable researchers to more fully and critically consider the array of sites at which such interventions occur. Secondly, insights from prison sport and carceral geography literature may inform more nuanced theoretical analysis of time, space, social control, and resistance in and through SfD initiatives. Thirdly, considering the diffuse "mobile and embodied" (Moran et al., 2018, p. 670) effects of carcerality in SfD spaces could provide opportunities to more deeply understand the lived experiences of participants and the ways in which sport interventions empower or further marginalize them. Finally, by highlighting the links between SfD and diverse bodies of literature, particularly those focused on prison sport and carceral geography, this article supports ongoing efforts by SfD researchers to deepen engagement with critical interdisciplinary perspectives. As the critical SfD literature continues to expand its theoretical horizons and consider a wider range of types and locations of sport interventions, there is a great deal of potential for research to grapple with the complexities of carcerality that may be present in SfD interventions in diverse global settings. It is hoped that, by providing an initial effort to link the SfD and prison sport literatures and critically analyzing them in light of theoretical developments in carceral geography, this article has provided a platform upon which future research can advance.

\section{Acknowledgments}

This research was supported by a research grant from the Social Sciences and Humanities Research Council of Canada. The author would like to thank the anonymous reviewers for their insightful comments and Michael Dao for his thoughtful feedback on a draft of this manuscript.

\section{Conflict of Interests}

The author declares no conflict of interests. 


\section{References}

Andrews, G. J. (2017). From post-game to play-by-play: Animating sports movement-space. Progress in $\mathrm{Hu}$ man Geography, 41(6), 766-794.

Andrews, J. P., \& Andrews, G. J. (2003). Life in a secure unit: The rehabilitation of young people through the use of sport. Social Science \& Medicine, 56(3), 531-550.

Bale, J. (1993). The spatial development of the modern stadium. International Review for the Sociology of Sport, 28(2/3), 121-133.

Bustad, J. J., \& Andrews, D. L. (2017). Policing the void: Recreation, social inclusion and the Baltimore Police Athletic League. Social Inclusion, 5(2), 241-249.

Caputo-Levine, D. D. (2013). The yard face: The contributions of inmate interpersonal violence to the carceral habitus. Ethnography, 14(2), 165-185.

Chawansky, M., \& Hayhurst, L. M. (2015). Girls, international development and the politics of sport: Introduction. Sport in Society, 18(8), 877-881.

Coyle, A., \& Fair, H. (2018). A human rights approach to prison management: Handbook for prison staff. London: University of London.

Dao, M., \& Smith, T. (2019). The capability approach as a conceptual bridge for theory-practice in Sport-forDevelopment. Journal of Global Sport Management. https://doi.org/10.1080/24704067.2019.1703117

Darnell, S. (2012). Sport for development and peace: $A$ critical sociology. London: Bloomsbury.

Darnell, S. C., Chawansky, M., Marchesseault, D., Holmes, M., \& Hayhurst, L. (2018). The state of play: Critical sociological insights into recent 'sport for development and peace' research. International Review for the Sociology of Sport, 53(2), 133-151.

Darnell, S. C., \& Dao, M. (2017). Considering sport for development and peace through the capabilities approach. Third World Thematics: A TWQ Journal, 2(1), 23-36.

Darnell, S. C., Field, R., \& Kidd, B. (2019). The history and politics of sport-for-development. London: Palgrave Macmillan.

Donnelly, P., Atkinson, M., Boyle, S., \& Szto, C. (2011). Sport for development and peace: A public sociology perspective. Third World Quarterly, 32(3), 589-601.

Dukic, D., McDonald, B., \& Spaaij, R. (2017). Being able to play: Experiences of social inclusion and exclusion within a football team of people seeking asylum. Social Inclusion, 5(2), 101-110.

Dyck, C. B. (2011). Football and post-war reintegration: Exploring the role of sport in DDR processes in Sierra Leone. Third World Quarterly, 32(3), 395-415.

Ellis, R. (2013). Asylums and sport: Participation, isolation and the role of cricket in the treatment of the insane. The International Journal of the History of Sport, 30(1), 83-101.

Fishwick, E., \& Wearing, M. (2017). 'Unruly mobilities' in the tracking of young offenders and criminality: Un- derstanding diversionary programs as carceral space. In J. Turner \& K. Peters (Eds.), Carceral mobilities: Interrogating movement in incarceration (pp. 44-66). New York, NY: Routledge.

Forde, S. D. (2015). Fear and loathing in Lesotho: An autoethnographic analysis of sport for development and peace. International Review for the Sociology of Sport, 50(8), 958-973.

Forde, S. D., \& Kota, A. (2016). Football as a terrain of hope and struggle: Beginning a dialogue on social change, hope and building a better world through sport. Qualitative Research in Sport, Exercise and Health, 8(5), 444-455.

Forde, S. D., Waldman, D., Hayhurst, L., \& Frisby, W. (2017). Sport, development and social change. In M. L. Silk, D. Andrews, \& H. Thorpe (Eds.), Routledge handbook of physical cultural studies (pp. 568-579). New York, NY: Routledge.

Forsyth, J. (2013). Bodies of meaning: Sport and games at Canadian residential schools. In J. Forsyth \& A. R. Giles (Eds.), Aboriginal peoples and sport in Canada: Historical foundations and contemporary issues (pp. 15-34). Vancouver: UBC Press.

Fortune, D., Thompson, J., Pedlar, A., \& Yuen, F. (2010). Social justice and women leaving prison: Beyond punishment and exclusion. Contemporary Justice Review, 13(1), 19-33.

Fortune, D., \& Whyte, C. (2011). Re-imagining institutional spaces: The communitizing potential of leisure. Leisure/Loisir, 35(1), 19-35.

Foucault, M. (1977). Discipline and punish: The birth of the prison (A. Sheridan, trans.). New York, NY: Vintage Books.

Fusco, C. (2007). 'Healthification' and the promises of urban space: A textual analysis of place, activity, youth (PLAY-ing) in the city. International Review for the Sociology of Sport, 42(1), 43-63.

Gacek, J. (2017). 'Doing time' differently: Imaginative mobilities to/from inmates' inner/outer spaces. In J. Turner \& K. Peters (Eds.), Carceral mobilities: Interrogating movement in incarceration (pp. 73-84). New York, NY: Routledge.

Gallant, D., Sherry, E., \& Nicholson, M. (2015). Recreation or rehabilitation? Managing sport for development programs with prison populations. Sport Management Review, 18(1), 45-56.

Gill, N., Conlon, D., Moran, D., \& Burridge, A. (2018). Carceral circuitry: New directions in carceral geography. Progress in Human Geography, 42(2), 183-204.

Giulianotti, R. (2011). Sport, transnational peacemaking, and global civil society: Exploring the reflective discourses of "sport, development, and peace" project officials. Journal of Sport and Social Issues, 35(1), 50-71.

Global Detention Project. (2019). Global detention project annual report 2018. Geneva: Global Detention Project.

Gruneau, R. (2015). Sport, development and the chal- 
lenge of slums. In R. Field (Ed.), Playing for change: The continuing struggle for sport and recreation (pp. 33-64). Toronto: University of Toronto Press.

Hartmann, D. (2001). Notes on midnight basketball and the cultural politics of recreation, race, and at-risk urban youth. Journal of Sport and Social Issues, 25(4), 339-371.

Hayhurst, L. M. (2016). Sport for development and peace: A call for transnational, multi-sited, postcolonial feminist research. Qualitative Research in Sport, Exercise \& Health, 8(5), 424-443.

Hayhurst, L. M., \& Giles, A. (2013). Private and moral authority, self-determination, and the domestic transfer objective: Foundations for understanding sport for development and peace in Aboriginal communities in Canada. Sociology of Sport Journal, 30(4), 504-519.

Joseph, J. (2015). Physical culture and alternative rehabilitation: Qualitative insights from a martial arts intervention program. In W. Crichlow \& J. Joseph (Eds.), Alternative offender rehabilitation and social justice: Arts and physical engagement in criminal justice and community settings (pp. 55-77). New York, NY: Palgrave.

Kath, E., \& van Buuren, N. G. (2013). Soldados nunca mais: Child soldiers, football and social change in Rio de Janeiro's favelas. In N. Schulenkorf \& D. Adair (Eds.), Global sport-for-development: Critical perspectives (pp. 194-215). London: Palgrave Macmillan.

Martinez-Merino, N., Martos-García, D., LozanoSufrategui, L., Martín-González, N., \& Usabiaga, O. (2019). Frictions, cracks and micro-resistances: Physical activity and sport as strategies to dignify imprisoned women. Qualitative Research in Sport, Exercise and Health, 11(2), 217-230.

Martos-García, D., Devís-Devís, J., \& Sparkes, A. C. (2009). Sport and physical activity in a high security Spanish prison: An ethnographic study of multiple meanings. Sport, Education and Society, 14(1), 77-96.

McGee, D., \& Pelham, J. (2018). Politics at play: Locating human rights, refugees and grassroots humanitarianism in the Calais Jungle. Leisure Studies, 37(1), 22-35.

Meek, R. (2014). Sport in prison: Exploring the role of physical activity in correctional settings. New York, NY: Routledge.

Meek, R., \& Lewis, G. (2014). The impact of a sports initiative for young men in prison: Staff and participant perspectives. Journal of Sport and Social Issues, 38(2), 95-123.

Moran, D. (2012). “Doing time” in carceral space: Timespace and carceral geography. Geografiska Annaler: Series B, Human Geography, 94(4), 305-316.

Moran, D. (2015). Carceral geography: Spaces and practices of incarceration. New York, NY: Routledge.

Moran, D., Turner, J., \& Schliehe, A. K. (2018). Conceptualizing the carceral in carceral geography. Progress in Human Geography, 42(5), 666-686.

Mullan, M. L. (1999). Sport, ethnicity and the reconstruc- tion of the self: Baseball in America's internment camps. The International Journal of the History of Sport, 16(1), 1-21.

Nols, Z., Haudenhuyse, R., \& Theeboom, M. (2017). Urban sport-for-development initiatives and young people in socially vulnerable situations: Investigating the 'deficit model.' Social Inclusion, 5(2), 210-222.

Norman, M. (2015). Prison yoga as a correctional alternative? Physical culture, rehabilitation, and social control in Canadian prisons. In W. Crichlow \& J. Joseph (Eds.), Alternative offender rehabilitation and social justice: Arts and physical engagement in criminal justice and community settings (pp. 78-98). New York, NY: Palgrave.

Norman, M. (2017). Sport in the underlife of a total institution: Social control and resistance in Canadian prisons. International Review for the Sociology of Sport, 52(5), 598-614.

Norman, M. (2018a). Physical activity in prisons. In J. Piggin, L. Mansfield, \& M. Weed (Eds.), Routledge handbook of physical activity policy and practice (pp. 342-355). New York, NY: Routledge.

Norman, M. (2018b). Researching sport in a 'total institution': Reflections on research barriers and methodological adaptations in a study of prison physical culture. Qualitative Research in Sport, Exercise \& Health, 10(1), 17-31.

Norman, M. (2019). Transforming space? Spatial implications of yoga in prisons and other carceral sites. Race \& Yoga, 4(1), 1-16.

Norman, M., \& Andrews, G. J. (2019). The folding of sport space into carceral space: On the making of prisoners' experiences and lives. The Canadian Geographer/Le Géographe canadien, 63(3), 453-465.

Norman, M., Ricciardelli, R., \& Sonoda, J. (2020). Sport and youth incarceration: A scoping review. Manuscript in preparation.

Oxford, S., \& Spaaij, R. (2017). Critical pedagogy and power relations in sport for development and peace: Lessons from Colombia. Third World Thematics: $A$ TWQ Journal, 2(1), 102-116.

Philo, C. (2012). Security of geography/geography of security. Transactions of the Institute of British Geographers, 37(1), 1-7.

Sabo, D. (2001). Doing time, doing masculinity: Sports and prison. In D. Sabo, T.A. Kupers, \& W. London (Eds.), Prison masculinities (pp. 61-66). Philadelphia: Temple University Press.

Scherer, J., Koch, J., \& Holt, N. L. (2016). The uses of an inner-city sport-for-development program: Dispatches from the (real) creative class. Sociology of Sport Journal, 33(3), 185-198.

Schulenkorf, N., Sherry, E., \& Rowe, K. (2016). Sport for development: An integrated literature review. Journal of Sport Management, 30(1), 22-39.

Spaaij, R. (2011). Sport and social mobility: Crossing boundaries. London: Routledge.

Spaaij, R., Broerse, J., Oxford, S., Luguetti, C., McLach- 
lan, F., McDonald, B., . . Pankowiak, A. (2019). Sport, refugees, and forced migration: $A$ critical review of the literature. Frontiers in Sports and Active Living, 1(47). https://doi.org/10.3389/fspor.2019.00047

Sugden, J. (2010). Critical left-realism and sport interventions in divided societies. International Review for the Sociology of Sport, 45(3), 258-272.

Te Hiwi, B., \& Forsyth, J. (2017). "A rink at this school is almost as essential as a classroom": Hockey and discipline at Pelican Lake Indian Residential School, 1945-1951. Canadian Journal of History, 52(1), 80-108.

UNHCR. (2018). Refugee facts. United Nations High Commissioner for Refugees. Retrieved from https://www. unrefugees.org/refugee-facts/camps

van Ingen, C. (2004). Therapeutic landscapes and the reg- ulated body in the Toronto Front Runners. Sociology of Sport Journal, 21(3), 253-269.

Wahidin, A. (2006). Time and the prison experience. Sociological Research Online, 11(1), 1-10.

Walmsley, R. (2017). World female imprisonment list (4th ed.). London: International Centre for Prison Studies.

Walmsley, R. (2018). World prison population list (12th ed.). London: International Centre for Prison Studies.

Willis, O. (2000). Sport and development: The significance of Mathare Youth Sports Association. Canadian Journal of Development Studies/Revue canadienne d'études du développement, 21(3), 825-849.

Yuen, F., Arai, S., \& Fortune, D. (2012). Community (dis)connection through leisure for women in prison. Leisure Sciences, 34(4), 281-297.

\section{About the Author}

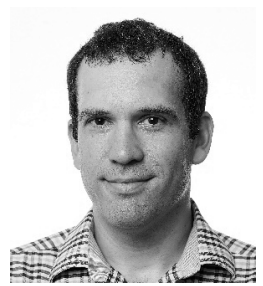

Mark Norman is a Postdoctoral Fellow in the Department of Health, Aging \& Society at McMaster University, Canada. He holds a PhD in Exercise Sciences (University of Toronto) and a master's degree in International Studies (Simon Fraser University). His primary area of research is focused on sport, physical culture, and incarceration. He is currently leading a project on sport and recreation in youth custody in Ontario, Canada, which is supported in part by funding from the Social Sciences and Humanities Research Council. 